\title{
Pumiliotoxin-B and Some of its Isomeric Structures - A DFT Study
}

\section{Lemi Türker}

Department of Chemistry, Middle East Technical University, Üniversiteler, Eskişehir Yolu No: 1, 06800 Çankaya/Ankara, Turkey; e-mail: lturker@gmail.com; lturker@metu.edu.tr

\begin{abstract}
Pumiliotoxin-B is an alkaloid produced by dart-poison frogs which are colorful and petite amphibians native to Caribbean region. In the present density functional treatment at the level of B3LYP/6-31G(d), pumiliotoxin-B and some of its isomeric structures are considered. Some structural and molecular orbital characteristics of them are investigated. These isomeric structures of pumiliotoxin-B include the enol and keto tautomers as well as the epoxide built on the double bond having $E$ configuration. The calculations have indicated the enol form to be more stable than the keto form, which might be attributed to possibility of more and better hydrogen bonding facility in the enol form. Another striking result obtained by both the thermodynamic and molecular orbital calculations is that the enol form is more stable than pumiliotoxin-B in vacuum conditions.
\end{abstract}

\section{Introduction}

The alkaloid pumiliotoxin-B (PTX-B， (E,2R,3R,8Z)-8-[(8S,8aS)-8-hydroxy-8methyl-1,2,3,5,7,8a-hexahydroindolizin-6-ylidene]-4,7-dimethyloct-4-ene-2,3-diol) is a novel indolizidine alkaloid from the skin of the Panamanian frog, Dendrobates pumilio [1]. Poison dart frog is the common name of a group of frogs in the family Dendrobatidae which are native to tropical Central and South America. These species are diurnal and often have brightly colored bodies. This bright coloration is correlated with the toxicity of the species, making them aposematic. Pumiliotoxin-B has the empirical formula of $\mathrm{C}_{19} \mathrm{H}_{33} \mathrm{NO}_{3}$ (MW: $323.477 \mathrm{~g} / \mathrm{mol}$ ). Its $2 \mathrm{D}$ formula is the following

\section{Received: April 8, 2019; Accepted: May 7, 2019}

Keywords and phrases: pumiliotoxin-B, PTX-B, poison dart frog, Dendrobatidae, DFT.

Copyright (C) 2019 Lemi Türker. This is an open access article distributed under the Creative Commons Attribution License, which permits unrestricted use, distribution, and reproduction in any medium, provided the original work is properly cited. 


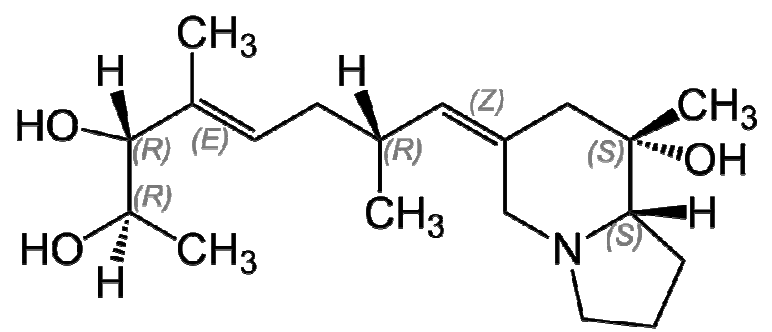

The structure has five chiral centers. Of these (R) type ones reside on the acyclic part of the molecule whereas $(S)$ centers are in the ring moiety. The two double bonds have $(E)$ and $(Z)$ configurations.

Enantioselective total syntheses of pumiliotoxin-B has been achieved [2]. Some other syntheses of it are described [3-5]. Gardiner and coworkers reported an approach towards C12 oxo analogues of the side chain of pumiliotoxin-B/allopumiliotoxin 339A and B [6]. Biochemical studies have revealed that PTX-B inhibits calcium-dependent adenosine triphosphatase from sarcoplasmic reticulum preparations of both frog and rat skeletal muscles in a concentration- and calcium-dependent manner [1]. Some other effects of pumiliotoxin-B have been investigated [7-15].

There is no computational study (up to the best knowledge of the author) on pumiliotoxin- $B$ in the literature. In the present study a density functional study of pumiliotoxin-B, its tautomers and isomeric oxo derivative has been presented.

\section{Method of Calculations}

The geometry optimizations of all the structures presently considered, leading to energy minima were achieved first by using MM2 method $[16,17]$ for the equilibrium conformer. Subsequent optimizations were achieved at Hartree-Fock level using various basis sets hierarchically. Then, the geometry optimizations were managed within the framework of density functional theory $[18,19]$, finally at the levels of RB3LYP /6$31 \mathrm{G}(\mathrm{d})$. Note that the exchange term of B3LYP consists of hybrid Hartree-Fock and local spin density (LSD) exchange functions with Becke's gradient correlation to LSD exchange $[19,20]$. Note that the correlation term of B3LYP consists of the Vosko, Wilk, Nusair (VWN3) local correlation functional [21] and Lee, Yang, Parr (LYP) correlation correction functional [22]. The vibrational analyses have also been done. The total electronic energies are corrected for the zero point vibrational energy (ZPE). The stationary points to energy minima were proved in all the cases by calculating the second 
derivatives of energy with respect to the atom coordinates. The normal mode analysis for each structure yielded no imaginary frequencies for the $3 N-6$ vibrational degrees of freedom, where $N$ is the number of atoms in the system. This indicates that the structure of each molecule corresponds to at least a local minimum on the potential energy surface. All these calculations were done by using the Spartan 06 package program [23].

\section{Results and Discussion}

The presence of embedded allyl alcohol moiety in pumiliotoxin-B allows the occurrence of some isomerization reactions, some of which falls into the category of tautomerism. Figure 1 displays the interrelationship among the structures. Although the conversions in the figure are shown as reversible, some of them may require an acid or base catalysis. However, it is to be noted that some of the forward and backward reactions may not be a feasible processes thermodynamically.

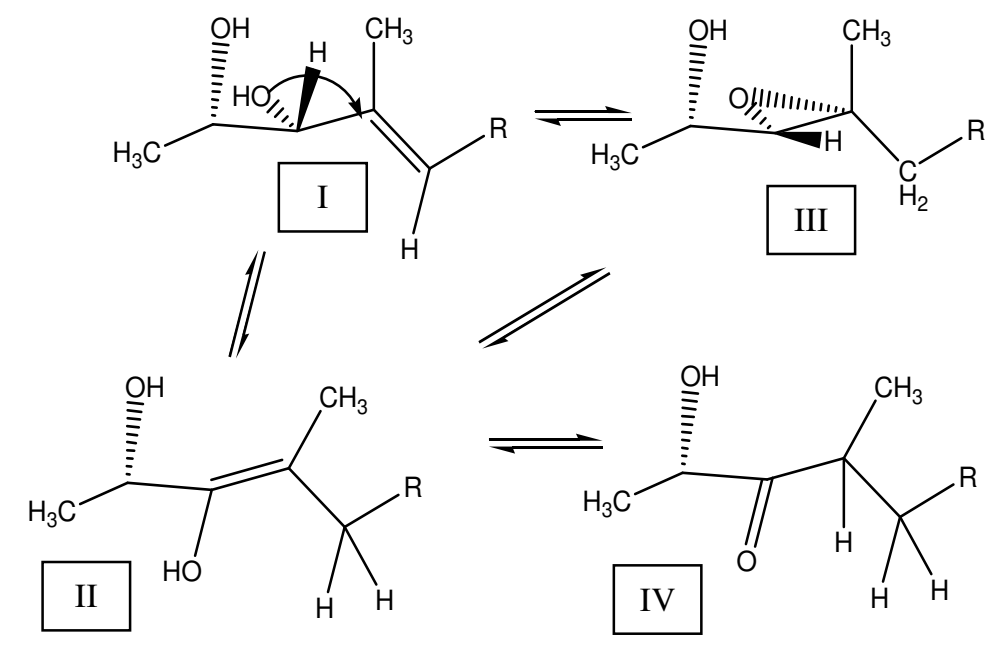

Figure 1. Interrelationship among the structures considered.

The conversion of I to III resembles a reaction involving an internal nucleophilic attack. The conversion II to IV is a simple 1,3-proton tautomerism. Whereas the conversion of I to II can happen in theory either by a 1,3-hydrogen shift or via the epoxide form. The second route seems to be more likely at the ambidient conditions.

Figure 2 shows the optimized structures of molecules of present concern. These are pumiliotoxin-B, its enol and keto forms and its epoxide. Note that all of these structures 
are isomeric $\left(\mathrm{C}_{10} \mathrm{H}_{33} \mathrm{NO}_{3}\right)$. The figure also shows the direction of the dipole moment vectors. Due to the flexibility of the structures, the direction of the dipole moment vectors change from structure to structure.
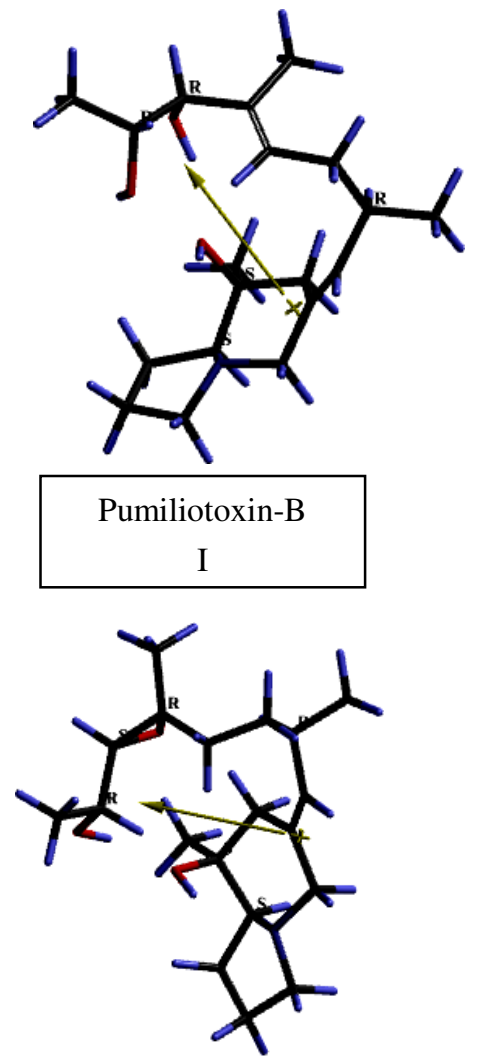

Epoxide form

III
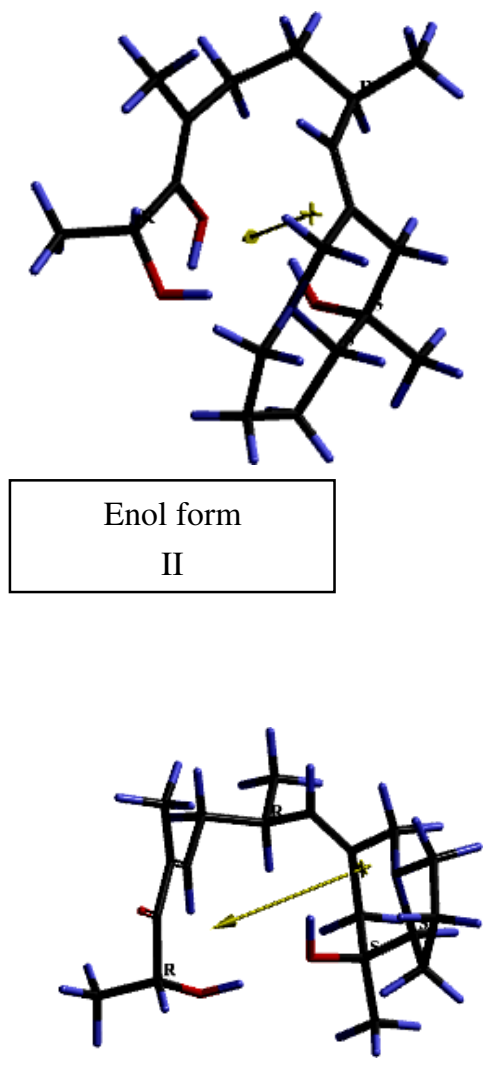

Keto form

IV

Figure 2. Optimized structures of the present concern.

Tables 1 and 2 show some thermodynamic properties of the structures considered and $\Delta G^{\circ}$ values for the indicated conversions, respectively. As seen in Table 2 conversion of I to II is the thermodynamically favored one. For the rest the reverse conversions are likely to occur. Note that the enol form is highly favorable over the keto form. This result, at the first sight might be somewhat unexpected. However, in the enol form more hydrogen bonding exist compared to the keto form (see Figure 3). This fact might be the stabilizing factor for the enol form. Table 3 shows some properties of the structures considered. 
Table 1. Some thermodynamic properties of the structures considered.

\begin{tabular}{lcccc}
\hline & $\begin{array}{c}\text { Pumiliotoxin-B } \\
\text { I }\end{array}$ & $\begin{array}{c}\text { Enol form } \\
\text { II }\end{array}$ & $\begin{array}{c}\text { Epoxide form } \\
\text { III }\end{array}$ & $\begin{array}{c}\text { Keto form } \\
\text { IV }\end{array}$ \\
\hline $\mathrm{H}^{\mathrm{o}}$ & -2687892.112 & -2687913.51 & -2687871.685 & -2684812.606 \\
$\mathrm{~S}^{\mathbf{o}}$ & 596.938011 & 590.92 & 592.48 & 591.55 \\
$\mathrm{G}^{\mathrm{o}}$ & -2688070.07 & -2688089.709 & -2688048.331 & -2684988.989 \\
$* \mathrm{CV}$ & 292.913742 & 290.79 & 290.77 & 285.83 \\
$* * \Delta \mathrm{H}_{\mathrm{f}}^{\circ}$ & -601.958 & -606.606 & -517.291 & -536.324 \\
\hline
\end{tabular}

Energies in $\mathrm{kJ} / \mathrm{mol}, * \mathrm{~J} / \mathrm{mol}^{\circ}, * * \mathrm{PM} 3 / / \mathrm{B} 3 \mathrm{LYP} / 6-31 \mathrm{G}(\mathrm{d})$

Table 2. $\Delta \mathrm{G}^{\mathrm{o}}$ values for the indicated conversions.

\begin{tabular}{cccc}
\hline $\mathrm{I} \rightarrow \mathrm{II}$ & $\mathrm{I} \rightarrow \mathrm{III}$ & $\mathrm{II} \rightarrow \mathrm{III}$ & $\mathrm{II} \rightarrow \mathrm{IV}$ \\
\hline-19.639 & 21.739 & 41.378 & 3100.72 \\
\hline
\end{tabular}

Energies in $\mathrm{kJ} / \mathrm{mol}$.
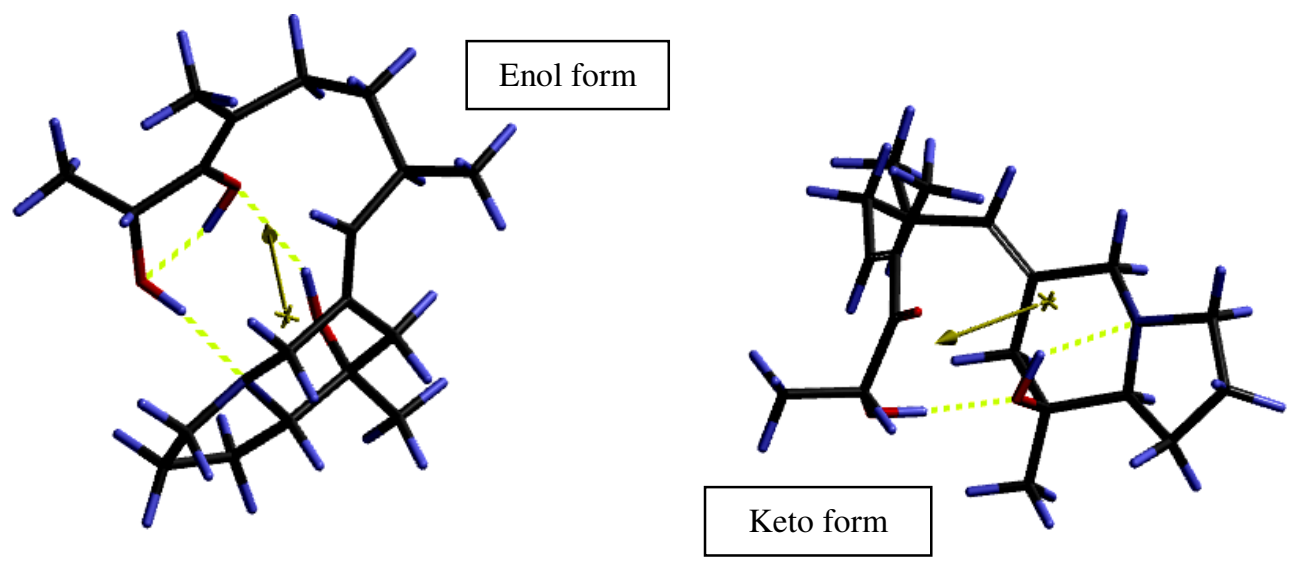

Figure 3. Hydrogen bonds in the enol and keto forms considered. 
Table 3. Some properties of the structures considered.

\begin{tabular}{ccccc}
\hline & Pumiliotoxin-B & Enol form & Epoxide form & Keto form \\
\hline Area $\left(\AA^{2}\right)$ & 381.74 & 374.71 & 381.92 & 379.60 \\
Volume $\left(\AA^{3}\right)$ & 364.26 & 362.53 & 362.61 & 359.40 \\
Ovality & 1.55 & 1.52 & 1.55 & 1.55 \\
Log P & 1.52 & 1.39 & 1.43 & 2.17 \\
$\begin{array}{c}\text { Polarizability } \\
\text { Dipole (debye) }\end{array}$ & 69.38 & 69.44 & 69.20 & 69.36 \\
$\begin{array}{c}\text { Similarity to } \\
\text { pumiliotoxin-B } \\
(\text { RMS } \AA \text { ) }\end{array}$ & 2.74 & 3.21 & 3.45 & 5.14 \\
\hline
\end{tabular}

All have $\mathrm{C} 1$ point group.

Figure 4 shows the IR spectra of the species considered. Pumiliotoxin-B has a sharp $\mathrm{O}-\mathrm{H}$ stretching at $3560 \mathrm{~cm}^{-1}$. It is the $\mathrm{OH}$ attached the carbon also having the terminal methyl group. The other $\mathrm{OH}$ groups have rather weak $\mathrm{O}-\mathrm{H}$ stretchings. In the enol spectrum the same stretching occurs at $3271 \mathrm{~cm}^{-1}$. The other O-H stretchings are weak. The epoxide isomers have just two $\mathrm{O}-\mathrm{H}$ stretchings at close to each other. The carbonyl band of IV is unexpectedly not strong.

Figures 5 and 6 display the natural and ESP charges, respectively. Note that the ESP charges are obtained by the program based on a numerical method that generates charges that reproduce the electrostatic potential field from the entire wavefunction [23]. The natural and ESP charges displayed in Figures 5 and 6 , have of course different magnitudes on the respective atoms but in sign they are in accord.

Table 4 shows the total electronic energy (E) zero point vibrational energy (ZPE) and corrected total electronic energy $\left(\mathrm{E}_{\mathrm{c}}\right)$. The order of stabilities is II $>$ I $>$ III $>$ IV (Reverse order of $E_{c}$ values). As mentioned above, the enol tautomer appears to be more stable than pumiliotoxin-B and the rest. 

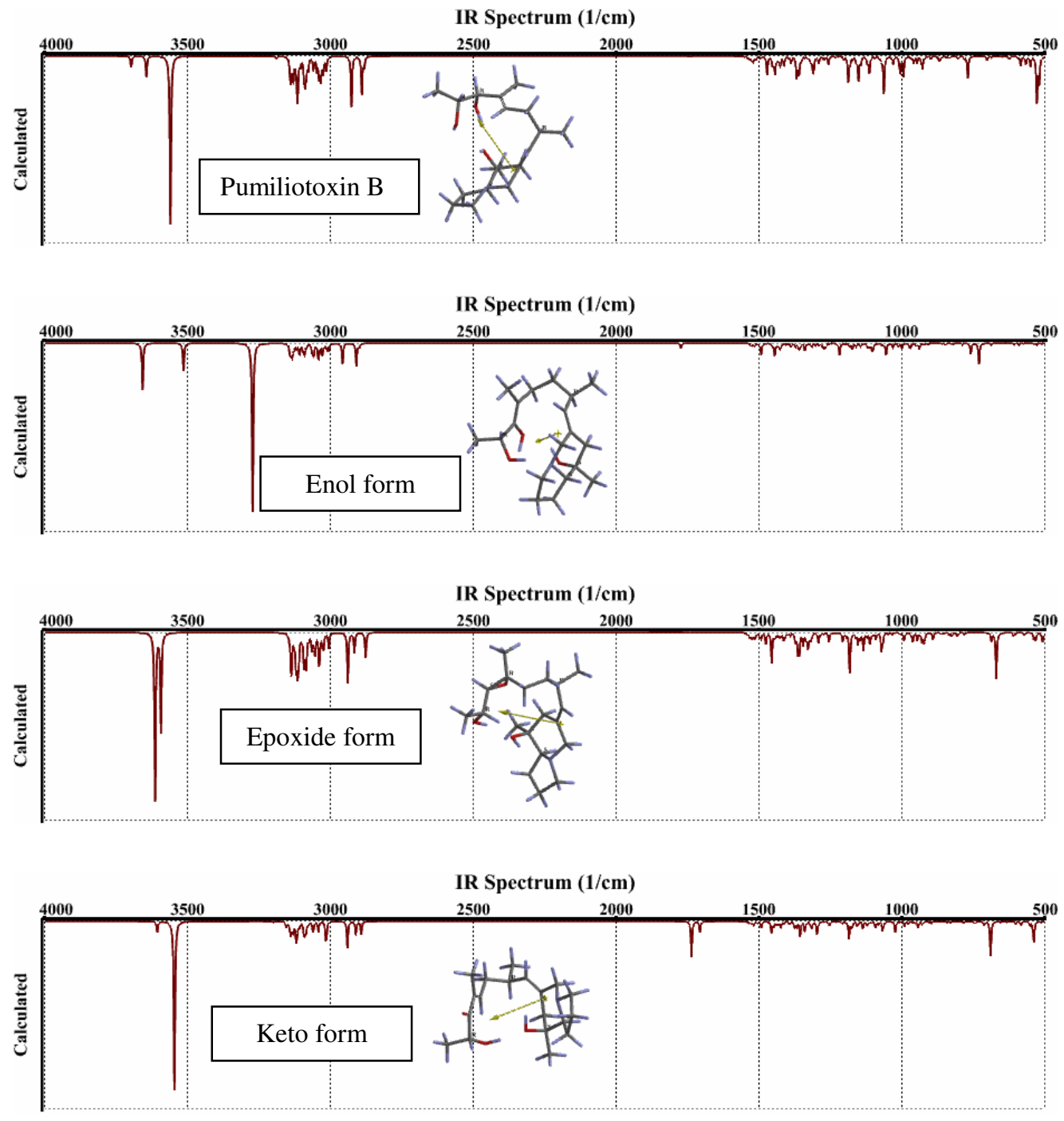

Figure 4. IR spectra of the structures considered. 

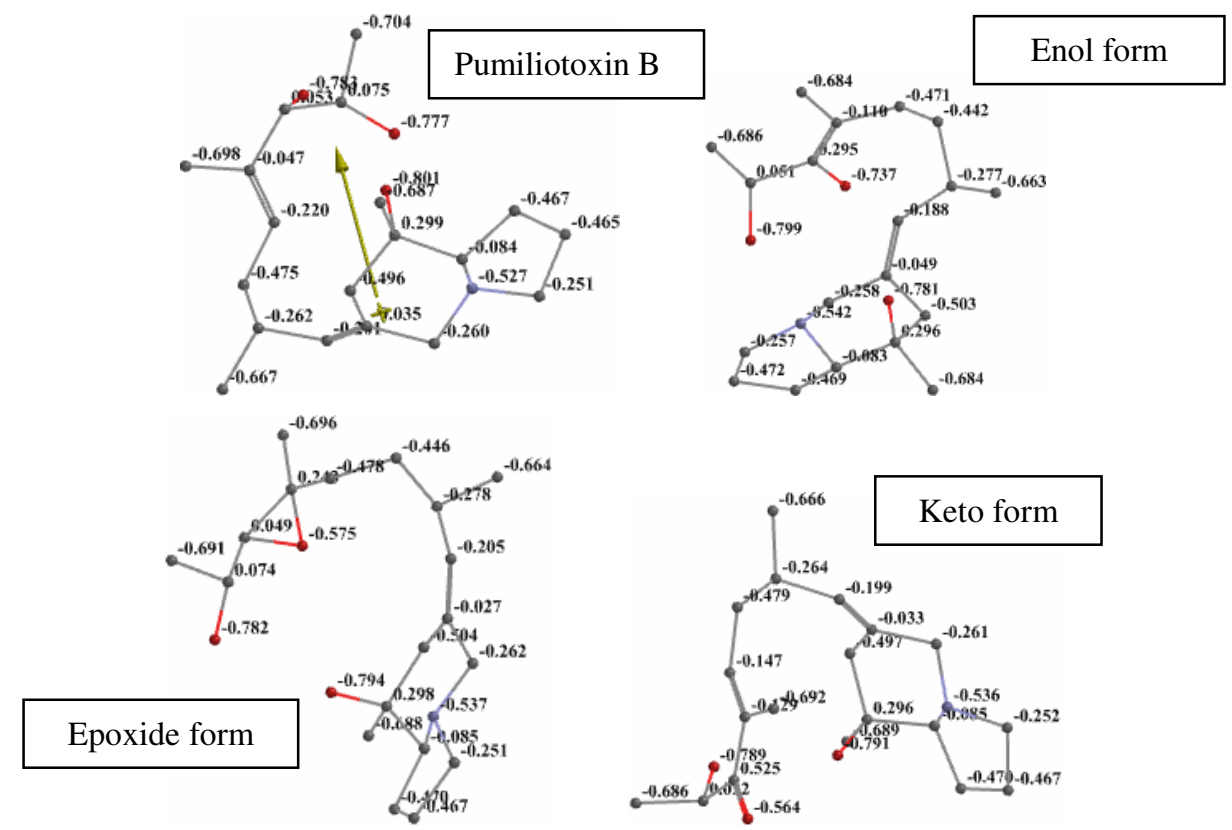

Figure 5. Natural charges on the atoms of the structures considered (hydrogens omitted).
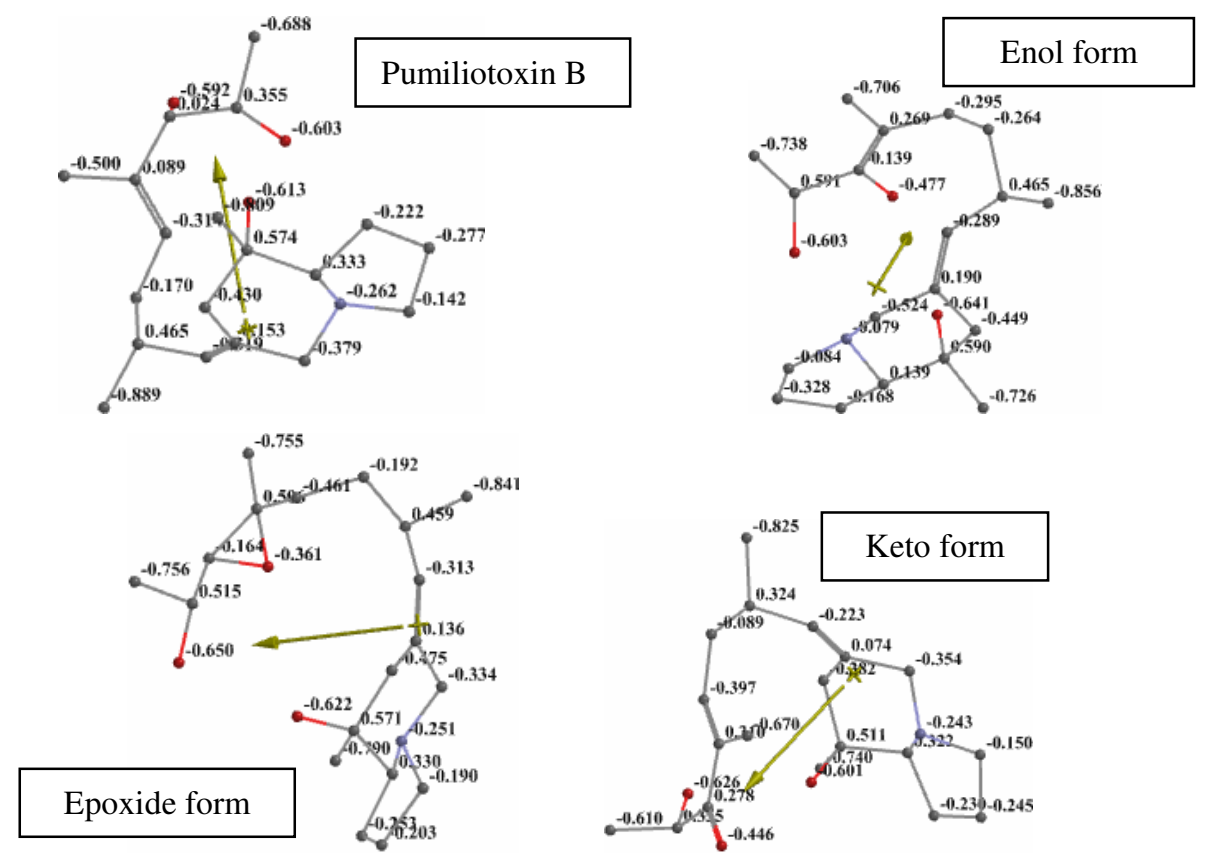

Figure 6. ESP charges on the atoms of the structures considered (hydrogens omitted). 
Table 4. Some energies of the structures considered.

\begin{tabular}{cccc}
\hline Structure & $\mathbf{E}$ & $\mathbf{Z P E}$ & $\mathbf{E}_{\mathbf{c}}$ \\
\hline $\begin{array}{c}\text { Pumiliotoxin-B } \\
\text { I }\end{array}$ & -2689247.65 & 1323.04 & -2687924.61 \\
Enol form & -2689270.93 & 1325.51 & -2687945.42 \\
II & & & \\
Epoxide form \\
III \\
Keto form \\
IV
\end{tabular}

Energies in $\mathrm{kJ} / \mathrm{mol}$.

Figure 7 shows some molecular orbital energy levels of the structures considered. Pumiliotoxin-B is characterized with the HOMO energy which is the next lowest after the respective energy of the epoxide form (Table 5). The order of HOMO and LUMO energies are III $<\mathrm{I}<\mathrm{IV}<\mathrm{II}$ and IV $<\mathrm{II}<\mathrm{I}<\mathrm{III}$, respectively. Note that except the keto form, all the rest have positive LUMO energies. Apparently, the keto group lowers the LUMO energy compared to the others. The order of interfrontier molecular orbital energy gaps is IV $<$ II $<$ I $<$ III. Since, $\Delta \varepsilon$ value for the keto tautomer is the smallest of all, UV-VIS spectrum of it absorbs comparatively at longer wavelenghts. Its consequence is (as seen in Figure 8) a bathochromic effect. The figure is time-dependent UV-VIS spectra of the structures considered. From Figure 7 it is evident that the NEXT HOMO and NEXT LUMO levels of the enol form are rather apart from the HOMO and LUMO levels, respectively. The epoxide form possesses nearly spaced HOMO and NEXT HOMO levels. Note that nearly spaced molecular orbitals have similar contributions to the chemical reactivity of a molecule.

Table 5 shows the HOMO, LUMO energies and the interfrontier molecular orbital gaps $(\Delta \varepsilon)$ of the structures considered.

Figure 8 displays the time dependent UV-VIS spectra of the structures considered. The keto form has a distinct spectrum having two maximas and the bathochromic effect exhibited. 


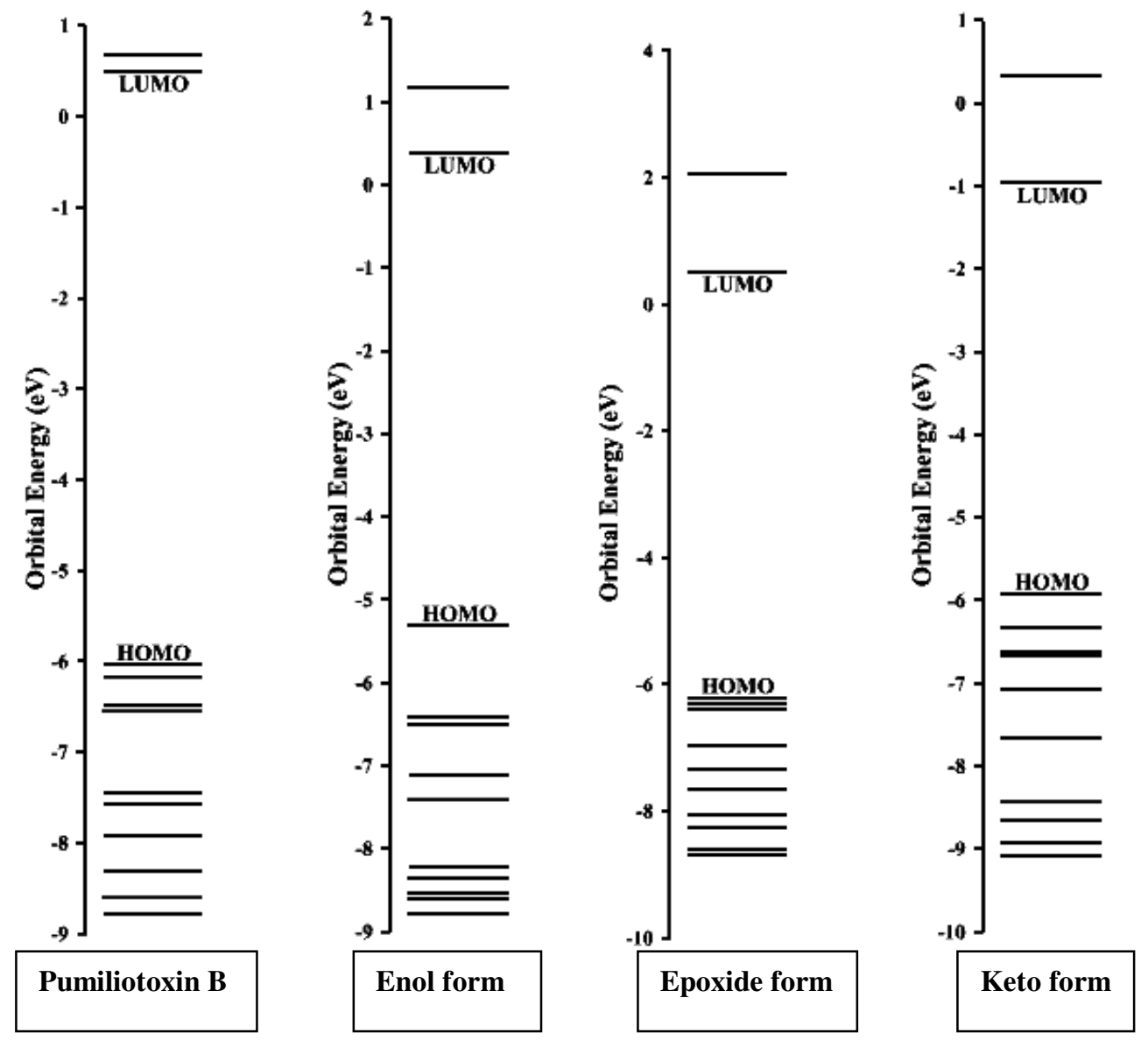

Figure 7. Some molecular orbital energy levels of the structures considered.

Table 5. The HOMO, LUMO energies and the interfrontier molecular orbital gaps $(\Delta \varepsilon)$.

\begin{tabular}{lccc}
\hline & HOMO & LUMO & $\Delta \varepsilon$ \\
\hline Pumiliotoxin-B & -582.81 & 47.97 & 630.79 \\
Enol form & -512.60 & 37.29 & 549.89 \\
Epoxide form & -599.03 & 49.21 & 648.24 \\
Keto form & -571.50 & -93.06 & 478.44 \\
\hline
\end{tabular}

Energies in $\mathrm{kJ} / \mathrm{mol}$. 

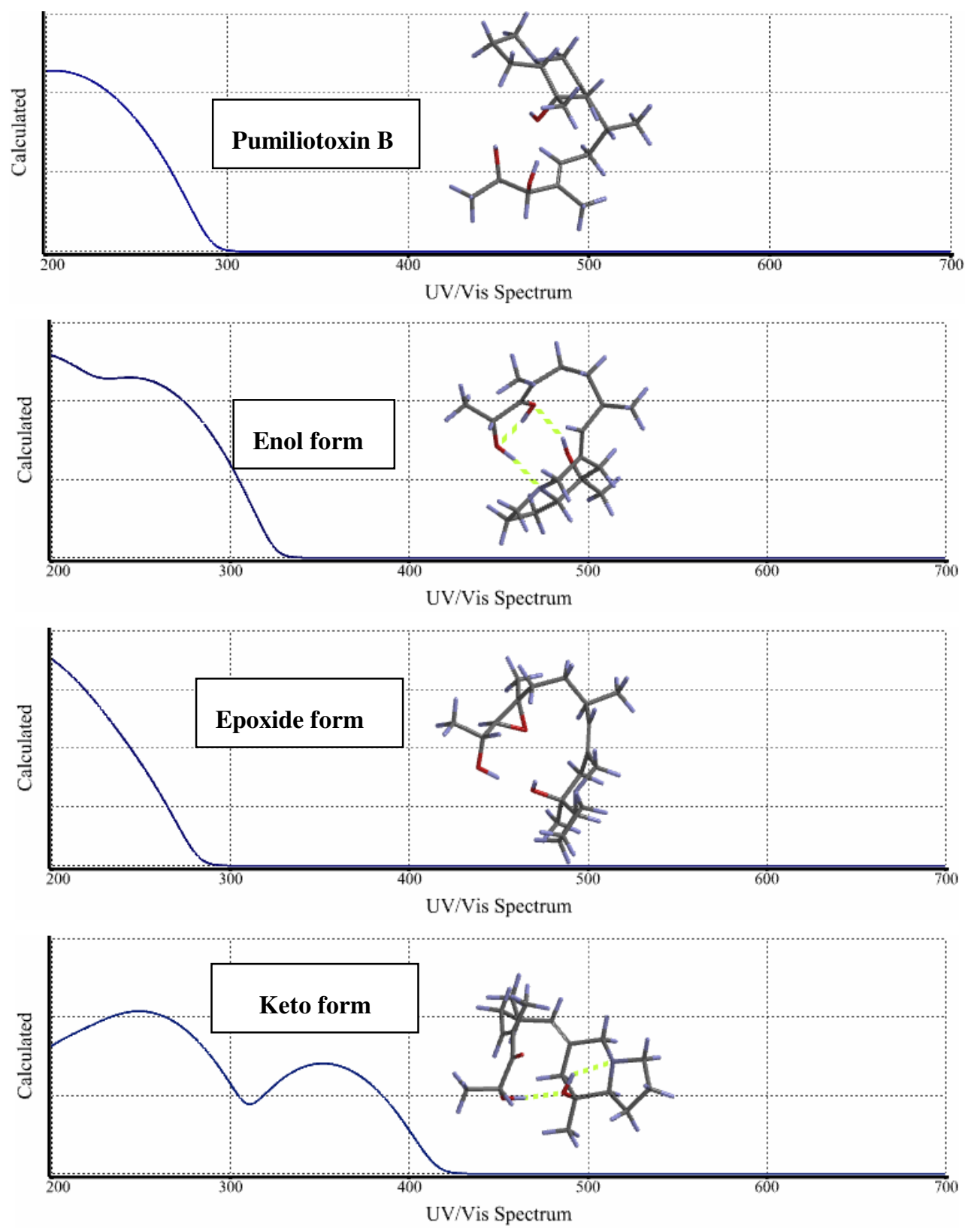

Figure 8. UV-VIS spectra of the species considered.

Figure 9 displays the HOMO and LUMO pattern of the structures considered. Although, the keto form does not contribute into both the HOMO and LUMO, the others do in varying degrees. 

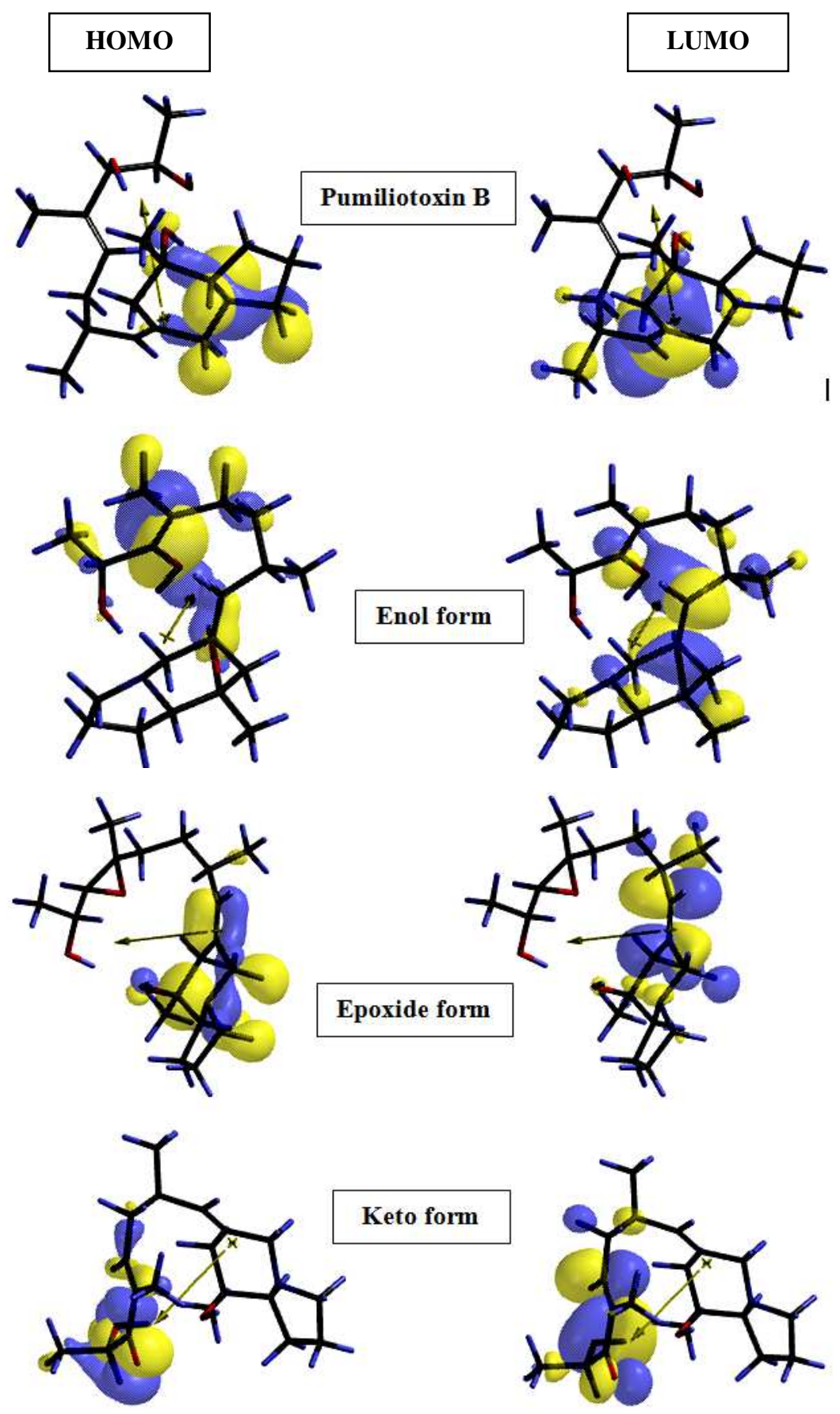

Figure 9. The HOMO and LUMO pattern of the structures considered. 


\section{Conclusion}

The present DFT treatment on pumiliotoxin-B and some of its isomeric structures has revealed that they are all stable structures. However, the enol form seems to be more stable than pumiliotoxin-B and the rest. The thermodynamic considerations based on $\Delta \mathrm{G}^{\circ}$ for the conversion of pumiliotoxin-B in to its enol form indicate favorability of it. The stability of the enol form is attributed to better and more hydrogen bond forming capability of it over pumiliotoxin-B. However, at present no information is available about the activation barriers of the conversions considered

\section{References}

[1] E.X. Albuquerque, J.E. Warnick, M.A. Maleque, F.C. Kauffman, R. Tamburini, Y. Nimit and J. W. Daly, The pharmacology of pumiliotoxin-B interaction with calcium sites in the sarcoplasmic reticulum of skeletal muscle, Mol. Pharmacol. 19(3) (1981), 411-424.

[2] L.E. Overman, K.L. Bell and F. Ito, Enantioselective total syntheses of pumiliotoxin-B and pumiliotoxin 251D. A general entry to the pumiliotoxin A alkaloids via stereospecific iminium ion-vinylsilane cyclizations, J. Am. Chem. Soc. 106(15) (1984), 4192-4201. https://doi.org/10.1021/ja00327a022

[3] S. Aoyagi, S. Hirashima, K. Saito and C. Kibayashi, Convergent approach to pumiliotoxin alkaloids. Asymmetric total synthesis of (+)-pumiliotoxins A, B, and 225F, Journal of Organic Chemistry 67(16) (2002), 5517-5526. https://doi.org/10.1021/jo0200466

[4] C. Kibayashi and S. Aoyagi, A convergent total synthesis of pumiliotoxins A and B via palladium-catalyzed cross-coupling reaction of homoallylic organozinc compounds with vinyl iodides, Journal of Organometallic Chemistry 653(1-2) (2002), 229-233. https://doi.org/10.1016/S0022-328X(02)01160-9

[5] A. Sudau, W. Münch, J.W. Bats and U. Nubbemeyer, Synthesis of the bicyclic core of pumiliotoxins, European Journal of Organic Chemistry (19) (2002), 3304-3314. https://doi.org/10.1002/1099-0690(200210)2002:19<3304::AID-EJOC3304>3.0.CO;2-A

[6] J.M. Gardiner, P.E. Giles and M.L.M. Martín, An approach towards C12 oxo analogues of the side chain of pumiliotoxin-B/allopumiliotoxin 339A and B, Tetrahedron Letters 43(31) (2002), 5415-5418. https://doi.org/10.1016/S0040-4039(02)01071-7

[7] R.E. Sheridan, S.S. Deshpande, F.J. Lebeda and Michael Adler, The effects of pumiliotoxin-B on sodium currents in guinea pig hippocampal neurons, Brain Research 556(1) (1991), 53-60. https://doi.org/10.1016/0006-8993(91)90546-8 
[8] F. Gusovsky, W.L. Padgett, C.R. Creveling and J.W. Daly, Interaction of pumiliotoxin B with an "alkaloid-binding domain" on the voltage-dependent sodium channel, Mol. Pharmacol. 42(6) (1992), 1104-1108.

[9] F. Gusovsky, D.P. Rossignol, E.T. McNeal and J.W. Daly, Pumiliotoxin-B binds to a site on the voltage-dependent sodium channel that is allosterically coupled to other binding sites, Proc. Natl. Acad. Sci. U.S.A. 85(4) (1988),1272-1276.

https://doi.org/10.1073/pnas.85.4.1272

[10] G.F. Erspamer, C. Severini, V. Erspamer and P. Melchiorri, Pumiliotoxin-B-like alkaloid in extracts of the skin of the Australian myobatrachid frog Pseudophryne coriacea: effects on the systemic blood pressure of experimental animals and the rat heart, Neuropharmacology 28(4) (1989), 319-328.

https://doi.org/10.1016/0028-3908(89)90025-7

[11] K.S. Rao, J.E. Warnick, J.W. Daly and E.X. Albuquerque, Pharmacology of the alkaloid pumiliotoxin-B. II. Possible involvement of calcium and sodium-dependent processes in nerve and skeletal muscle, J. Pharmacol. Exp. Ther. 243 (1987), 775-778.

[12] G.G. Schofield, F.F. Weight and S.R. Ikeda, The effect of pumiliotoxin-B on the excitability of bullfrog sympathetic neurons, Eur. J. Pharmacol. 89(2) (1988), 389-394.

[13] L. D’Este, G.F. Erspamer, C. Severini, V. Erspamer and T.G. Renda, Neuropeptide Y release by pumiliotoxin-B in the electrically-stimulated mouse vas deferens: an immunohistochemical study, T.G. Peptides 20(7) (1999), 809-816.

https://doi.org/10.1016/S0196-9781(99)00066-2

[14] R.W. Fitch and J.W. Daly, Phosphorimaging detection and quantitation for isotopic ion flux assays, Anal. Biochem. 342(2) (2005), 260-270.

https://doi.org/10.1016/j.ab.2005.04.041

[15] O. Sacchi, R. Bardoni, P.C. Magherini and O. Belluzzi, Electrophysiological effects of a neurotoxin extracted from the skin of the Australian frog Pseudophryne coriacea, Comp. Biochem. Physiol. C: Comp. Pharmacol. Toxicol. 103(2) (1992), 291-297.

https://doi.org/10.1016/0742-8413(92)90010-5

[16] A.R. Leach, Molecular Modeling, Essex: Longman, 1997.

[17] P. Fletcher, Practical Methods of Optimization, New York: Wiley, 1990.

[18] W. Kohn and L. Sham, Self-consistent equations including exchange and correlation Effects, J. Phys. Rev. 140 (1965), 1133-1138.

https://doi.org/10.1103/PhysRev.140.A1133 
[19] R.G. Parr and W. Yang, Density Functional Theory of Atoms and Molecules, London: Oxford University Press, 1989.

[20] A.D. Becke, Density-functional exchange-energy approximation with correct asymptotic behavior, Phys. Rev. A 38 (1988), 3098-3100. https://doi.org/10.1103/PhysRevA.38.3098

[21] S.H. Vosko, L. Vilk and M. Nusair, Accurate spin-dependent electron liquid correlation energies for local spin density calculations: a critical analysis, Can. J. Phys. 58 (1980), 1200-1211. https://doi.org/10.1139/p80-159

[22] C. Lee, W. Yang and R.G. Parr, Development of the Colle-Salvetti correlation-energy formula into a functional of the electron density, Phys. Rev. B 37(1988), 785-789. https://doi.org/10.1103/PhysRevB.37.785

[23] SPARTAN 06, Wavefunction Inc., Irvine CA, USA, 2006. 